\title{
The challenge of stopping the knocking down of metabolic dominos upstream
}

\author{
Tomohiro Katsuya and Ryuichi Morishita
}

Hypertension Research (2010) 33, 529-530; doi:10.1038/hr.2010.59; published online 13 May 2010

$\mathrm{T}$

he concept of the metabolic domino ${ }^{1}$ has become well known, not only to doctors but also to the general population in Japan. The Japanese people are familiar with metabolic syndrome in part because the Japanese Ministry of Health, Labor and Welfare has, since 2008, promoted a special checkup for the general population that focuses on metabolic syndrome. ${ }^{2}$ This national campaign was started as part of the promotion of a set of measures called 'Health Japan 21' that counteracts lifestyle-related disease. The goal of this campaign is to reduce the cost of medical care by improvements in lifestyle and earlier detection of premature cardiovascular disease. As a result, the main focus of the program is health checkups and the prevention of severe cardiovascular events, such as myocardial infarction or stroke, through the dissemination of appropriate nutrition information as well as the promotion of physical activity and exercise. The Ministry of Health, Labor and Welfare and the Ministry of Agriculture, Forestry and Fisheries jointly compiled a document entitled 'Dietary Guidelines for Japanese' and promoted a food and nutrition education program named 'Shokuiku'.

Even though the central concept of metabolic syndrome ${ }^{3,4}$ is based on visceral fat accumulation, hypertension also has a large role. The Japanese Society of Hypertension Guidelines for the Management of Hypertension (JSH2009) ${ }^{5}$ clearly state that the main diseases related to metabolic syndrome are cardiovascular disease and diabetes mellitus and that the target range for blood pressure control is $<130 / 85 \mathrm{~mm} \mathrm{Hg}$. In the table of

Dr T Katsuya and R Morishita are at the Department of Clinical Gene Therapy, Osaka University Graduated School of Medicine, 2-2 J4, Yamada-oka, Suita 565-0871, Japan.

E-mail: tkatsuya@iris.eonet.ne.jp risk stratification in JSH2009, the subjects with high-normal blood pressure (130-139/ $85-89 \mathrm{~mm} \mathrm{Hg}$ ) and metabolic syndrome are classified into risk stratum 2. The initial treatment for metabolic syndrome is the correction of abdominal obesity through dietary and exercise therapies. In the chapter on lifestyle modification in JSH2009, salt restriction, maintenance of appropriate body weight, exercise, alcohol restriction and cessation of smoking are recommended as effective techniques to reduce blood pressure and prevent hypertension. Asian populations are genetically predisposed to hypertension ${ }^{6}$ and metabolic syndrome ${ }^{7}$ because of higher salt sensitivity. As a result, control of body weight and reduction of visceral fat are critical to preventing future cardiovascular disease.

Recently, physicians have started administering medication in the early stages of lifestyle-related diseases, using drug therapy to achieve strictly defined target levels for various health indicators. For example, the results obtained from a 10 year follow-up in the United Kingdom Prospective Diabetes Study clearly suggested the importance of tightly controlling glucose levels in earlystage diabetes. ${ }^{8}$ In the same study, only the subjects who maintained a healthy blood pressure level continuously during the study period received the benefits of risk reduction for cardiovascular disease. ${ }^{9}$ In the treatment of hypertension, preventing onset of diabetes is an important issue. The Candesartan Antihypertensive Survival Evaluation in Japan trial ${ }^{10}$ showed that treatment using an angiotensin II receptor blocker, candesartan, had a more significant benefit in new-onset diabetes than did a Ca channel blocker, amlodipine. In the Trial of Preventing Hypertension (TROPHY) study, ${ }^{11}$ earlier use of an angiotensin II receptor blocker in subjects with prehypertension suppressed the onset of hypertension.
In contrast, recent results obtained from the Action to Control Cardiovascular Risk in Diabetes study ${ }^{12}$ suggest that intensive blood pressure control $(<120 \mathrm{~mm} \mathrm{Hg})$, as compared with moderate control $(<140$ $\mathrm{mmHg}$ ), does not reduce the rate of a composite outcome of fatal and nonfatal major cardiovascular events in patients with diabetes at high risk for cardiovascular events. These results suggest that earlier and continuous 'optimal' control of blood pressure and glucose reduces the risk of knocking down metabolic dominos and prevents hypertension, diabetes and cardiovascular disease. However, lagging and excessive control of blood pressure or glucose levels is not always a good thing for patients.

The idea of stopping the chain reaction of cardiovascular risks can be expressed using the metaphor of knocking down dominos. The size of the dominos increases from upstream to downstream. In other words, disease severity and medical care expenditures increase as more dominos are knocked down. Thus, stopping dominos from being knocked down upstream is most important for public health.

Otsuka et al. ${ }^{13}$ examined the correlation between the number of metabolic syndrome components and dietary factors in middleaged and elderly Japanese subjects; their results indicated that different dietary factors are correlated with metabolic dominos in males and females. Even though the number of subjects examined was small, the results obtained seem useful when considering early interventions that prevent the knocking down of dominos. A low intake of vitamin $\mathrm{B}_{6}$ and dietary fiber was associated with the number of metabolic components found in males. In females, a high intake of cereal and a low intake of calcium, milk and dairy food predisposed women to metabolic syndrome. 


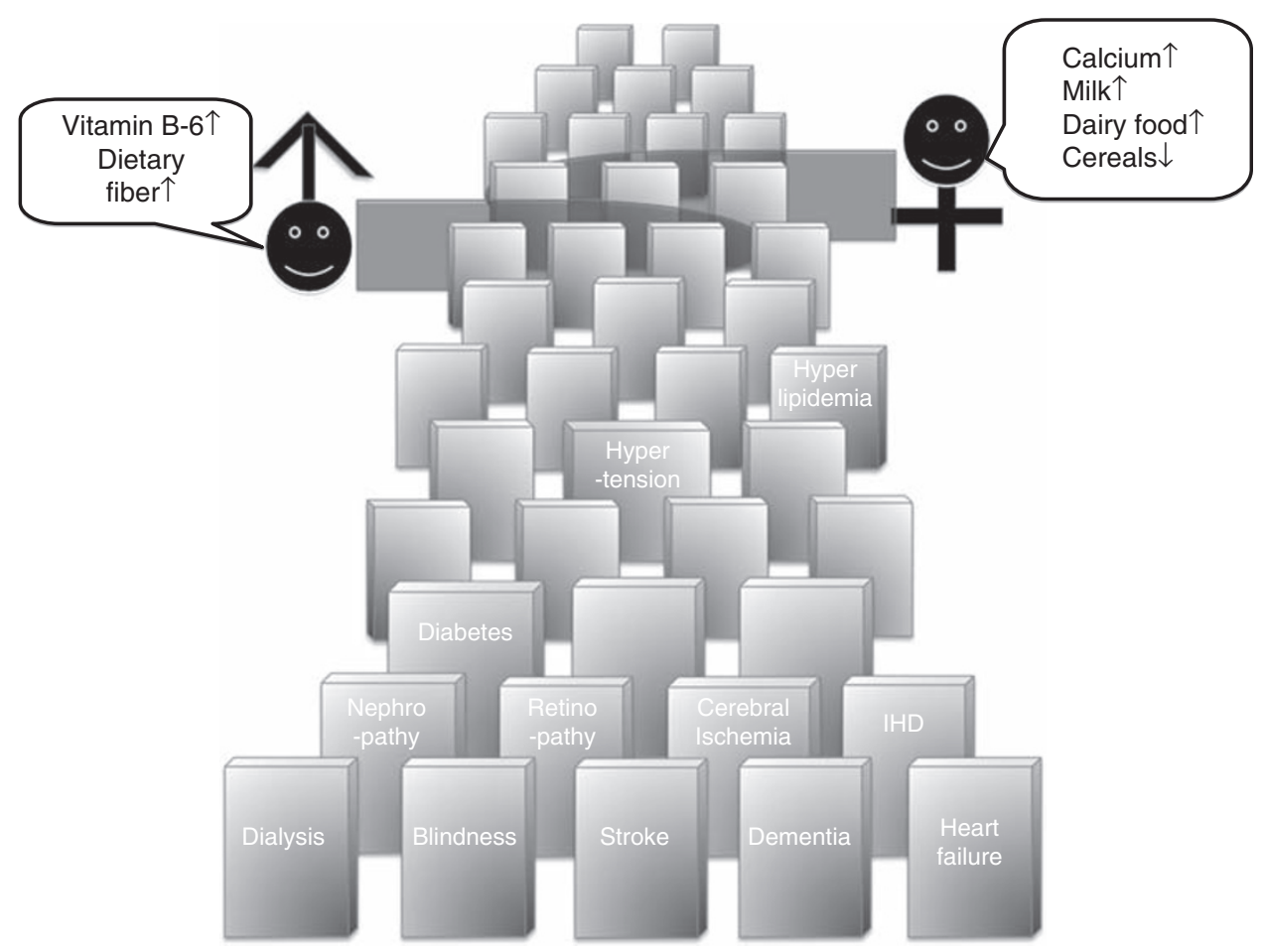

Figure 1 Ways to put an early stop to the metabolic domino effect. Useful lifestyle modifications, which differ for men and women, to stop the knocking down of metabolic dominos upstream. ${ }^{1,13}$

It is conceivable that lifestyle modifications to address these findings could decrease the risk of knocking down metabolic dominos upstream (Figure 1). In younger generations in Japan, obesity is a social issue for men, and excess weight loss is a major problem for women. Young Japanese women tend to be anorexic because of their desire to be slim. As a result, the number of low-birth-weight babies is increasing, which will lead to an increase in future rates of metabolic syndrome. ${ }^{14}$ Thus, this investigation may be relevant to education programs such as 'Shokuiku' that address the optimal diet for younger generations. The conscious control of diet in daily life has an important role as a useful and thrifty strategy to stop the knocking down metabolic dominos.

1 Itoh H. Metabolic domino: new concept in lifestyle medicine. Drugs Today (Barc) 2006; 42(Suppl C): 9-16.
2 Ministry of Health, Labor and Welfare. Section 3. Measures against Lifestyle-Related Diseases through 'Health Japan 21' and Promotion of 'Shokuiku (food and nutrition education)'. Annual Health, Labor and Welfare Report 2007-2008. http://www.mhlw.go.jp/ english/wp/wp-hw2/part2/p2c1s3.pdf.

3 Committee to Evaluate Diagnostic Standards for Metabolic Syndrome. Definition and the diagnostic standards for metabolic syndrome. Nippon Naika Gakkai Zasshi 2005; 94: 794-809.

4 Expert Panel on Detection, Evaluation, And Treatment of High Blood Cholesterol In Adults. Executive Summary of The Third Report of The National Cholesterol Education Program (NCEP) Expert Panel on Detection, Evaluation, And Treatment of High Blood Cholesterol In Adults (Adult Treatment Panel III). JAMA 2001; 285: 2486-2497.

5 Ogihara T, Kikuchi K, Matsuoka H, Fujita T, Higaki J, Horiuchi M, Imai Y, Imaizumi T, Ito S, Iwao H, Kario K, Kawano Y, Kim-Mitsuyama S, Kimura G, Matsubara H, Matsuura H, Naruse M, Saito I, Shimada K, Shimamoto K, Suzuki H, Takishita S, Tanahashi N, Tsuchihashi T, Uchiyama M, Ueda S, Ueshima H, Umemura S, Ishimitsu T, Rakugi H. The Japanese Society of Hypertension Guidelines for the Management of Hypertension (JSH 2009). Hypertens Res 2009; 32: 3-107.

6 Katsuya T, Ishikawa K, Sugimoto K, Rakugi H, Ogihara T. Salt sensitivity of Japanese from the viewpoint of gene polymorphism. Hypertens Res 2003; 26: 521-525.

7 Chen J, Gu D, Huang J, Rao DC, Jaquish CE, Hixson JE, Chen CS, Chen J, Lu F, Hu D, Rice T, Kelly TN, Hamm $\mathrm{LL}$, Whelton PK, He J. Metabolic syndrome and salt sensitivity of blood pressure in non-diabetic people in China: a dietary intervention study. Lancet 2009; 373: 829-835.

8 Holman RR, Paul SK, Bethel MA, Matthews DR, Neil HA. 10-year follow-up of intensive glucose control in type 2 diabetes. N Engl J Med 2008; 359: 1577-1589.

9 Holman RR, Paul SK, Bethel MA, Neil HA, Matthews DR. Long-term follow-up after tight control of blood pressure in type 2 diabetes. N Engl J Med 2008; 359: 1565-1576.

10 Ogihara T, Nakao K, Fukui T, Fukiyama K, Ueshima K, Oba K, Sato T, Saruta T. Effects of candesartan compared with amlodipine in hypertensive patients with high cardiovascular risks: candesartan antihypertensive survival evaluation in Japan trial. Hypertension 2008; 51: 393-398.

11 Julius S, Nesbitt SD, Egan BM, Weber MA Michelson EL, Kaciroti N, Black HR, Grimm Jr RH, Messerli FH, Oparil S, Schork MA. Feasibility of treating prehypertension with an angiotensin-receptor blocker. N Engl J Med 2006; 354: 1685-1697.

12 The ACCORD Study Group. Effects of intensive bloodpressure control in type 2 diabetes mellitus. $N$ Engl J Med (e-pub ahead of print 14 March 2010).

13 Otsuka R, Imai T, Kato Y, Ando F, Shimokata H. Relation ship between number of metabolic syndrome components and dietary factors in middle-aged elderly Japanese subjects. Hypertens Res 2010; 33: 548-554.

14 Phillips DI, Jones A, Goulden PA. Birth weight, stress, and the metabolic syndrome in adult life. Ann N Y Acad Sci 2006; 1083: 28-36. 